\title{
Colaboração e Interação em Contextos Não Convencionais: aplicações e instalações artísticas e de entretenimento
}

\author{
Bruno Gadelha, Thaís Castro, \\ Rosiane de Freitas \\ Instituto de Computação \\ UFAM \\ Manaus - AM, Brasil \\ $\{$ bruno, thais, \\ rosiane\} @icomp.ufam.edu.br
}

\author{
Edna Cardoso \\ Instituto de Ciências Sociais, \\ Educação e Zootecnia \\ UFAM \\ Parintins - AM, Brasil \\ ednamagalhaes@gmail.com
}

\author{
Hugo Fuks \\ Departamento de Informática \\ PUC-Rio \\ Rio de Janeiro - RJ, Brasil \\ hugo@inf.puc-rio.br
}

\begin{abstract}
This paper presents an investigation that has been developed at the Federal University of Amazonas through projects involving concepts of collaborative systems(CS) and humancomputer interaction (HCI) in artistic-cultural and entertainment events scenarios. In the artistic scene, there have been projects involving music and interaction through sounds. In the scenario of large entertainment events involving crowds, the projects consider issues such as engagement, interaction and collaboration. In these unconventional contexts the importance of the integration between the SC and IHC areas is observed in order to achieve relevant results to change the behavior of the audience aiming at an active, participatory and interactive attitude in the field of the arts and entertainment for the crowds.
\end{abstract}

\section{Author Keywords}

Crowd computing; crowd engagement; crowd interaction; entertainment computing; arts and entertainment.

\section{ACM Classification Keywords}

H.5.2 User Interfaces: Interaction styles; H.5.3 Group and Organization Interfaces: synchronous interaction; H.5.5 Sound and Music Computing: systems; J.5 Arts and Humanities: Performing arts;

\begin{abstract}
APRESENTAÇÃO E CONTEXTO
"Uma das funções importantes da obra de arte é ser uma maneira de a sociedade se exibir, como um grupo e como uma série de indivíduos dentro de um grupo. O instrumento decisivo com o qual a obra ressoa não é tanto os indivíduos em si mesmos, cada qual sozinho com seus sentimentos, mas,

Permission to make digital or hard copies of all or part of this work for personal or classroom use is granted without fee provided that copies are not made or distributed for profit or commercial advantage and that copies bear this notice and the full citation on the first page. Copyrights for components of this work owned by others than the author(s) must be honored. Abstracting with credit is permitted. To copy otherwise, or republish, to post on servers or to redistribute to lists, requires prior specific permission and/or a fee. Copyright 2018 SBC.
\end{abstract}

IHC 2018, Anais Estendidos do XVII Simpósio Brasileiro sobre Fatores Humanos em Sistemas Computacionais Outubro 22-26, 2018, Belém, Brasil

Fórum de Integração e Discussão sobre Interação Humano-Computador e Sistemas Colaborativos (FID IHC-SC) muitos indivíduos integrados num grupo, pessoas cujos sentimentos são, em grande parte, mobilizados e orientados para o fato de estarem juntas. [1]". A citação de Bourdier [1] destaca a natureza colaborativa das artes de uma forma geral, que é realizada para fazer parte de um sistema complexo envolvendo o coletivo, consistindo em uma forma de expressão da sociedade. O trabalho criativo e lúdico, realizado pelas interações da sociedade com o meio consistem em um ponto de convergência entre Ciências, Artes e Educação [2].

Com base nessa convergência de áreas do saber e no fato da tecnologia permear e dar suporte transversal a todas essas áreas, a Faculdade de Artes da Universidade Federal do Amazonas (FAARTES/UFAM) realizou uma demanda ao Instituto de Computação da mesma universidade (IComp/UFAM) para realizar pesquisas conjuntas envolvendo música e tecnologia. Dessa parceria, surgiu o projeto "Uma abordagem colaborativa na composição dinâmica de música". O sucesso desse projeto levou os pesquisadores a pensar formas ainda maiores de integrar pessoas em situações ou instalações artísticas/culturais, principalmente aqueles envolvendo multidões.

O Brasil tem sido palco de grandes eventos esportivos e culturais. A realização da copa do mundo e dos últimos jogos olímpicos são exemplos disso. Outro exemplo é a realização de muitos festivais de música como o Rock in Rio e o Lolapalooza. Mais especificamente no cenário cultural da região Norte do país, onde a pesquisa tem sido desenvolvida, destacam-se diversos festivais folclóricos como, por exemplo, o Festival de Parintins, Festival de Cirandas de Manacapuru e a Festa do Peixe Ornamental de Barcelos. Esses eventos atraem multidões que, muitas vezes, limitamse a um papel secundário como expectador passivo desses eventos.

A necessidade de um maior engajamento em eventos dessa natureza é sentida pelo próprio público que, por iniciativa própria, encontra maneiras criativas de participar do espetáculo. Vale destacar que essas são iniciativas espontâneas que emergem da multidão e não são concebidas 
originalmente pelos organizadores do evento. Há casos, ainda, em que esse engajamento da audiência com o espetáculo é pensado e orquestrado pelos próprios organizadores do evento. A Figura 1 ilustra o engajamento do público em eventos de entretenimento, como por exemplo: uso de pulseiras que piscam ao som da banda Coldplay, torcida do Boi Bumbá Caprichoso no Festival Folclórico de Parintins fazendo um mosaico com pompons, torcida do time de futebol Flamengo montando um mosaico com placas de papel e, por último, reação espontânea da audiência do espetáculo de abertura das Olimpíadas Rio 2016 acendendo as lanternas do celular.
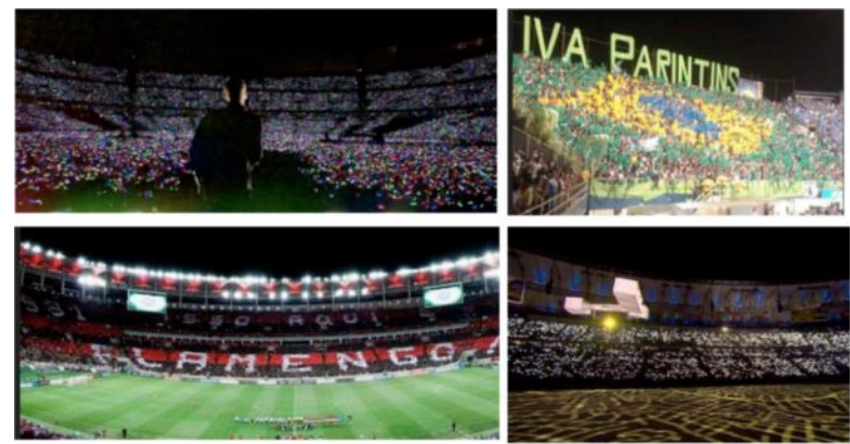

Figure 1. Exemplos de participação espontânea do público em eventos de entretenimento como mosaicos em estádios de futebol, $o$ acendimento da lanterna do celular na abertura das olimpíadas de 2016, em Parintins e no show da banda Coldplay.

Os exemplos apresentados deixam claro a importância do engajamento da audiência nos diferentes tipos de evento. Esse engajamento tem potencial de ser cada vez maior quando se tira proveito do poder de processamento dos artefatos digitais que são utilizados pela maioria das pessoas, como por exemplo o smartphone. Assim, as pesquisas que têm sido realizadas apontam para plataformas tecnológicas para o aumento do engajamento da audiência em eventos baseados em multidão (crowd-based events) [3, 4, 5], apoiada pelas teorias das dinâmicas de multidões (Crowd Dynamics) [6] e da computação e sensoriamento de multidões (Crowd Sensing and Computing) [7].

\section{OBJETIVOS}

As pesquisas que têm sido realizadas nesses contextos não convencionais têm por objetivo dar suporte tecnológico a novas formas de expressão artística e de engajamento público - espetáculo/evento. Espera-se, com isso, mudar a perspectiva do público que, a partir das interações entre si e com o objeto que está sendo apresentado (instalação artística, concerto, evento cultural ou esportivo, dentre outros) passe para um papel mais ativo e sirva como fonte de retroalimentação e modificação do objeto.

Para tanto, faz-se necessário:

1 - Caracterizar o comportamento das multidões no contexto do entretenimento com relação a: (1) atividades realizadas pelos grupos de pessoas; (ii) processos e estratégias para atingir o objetivo comum dos grupos de pessoas; (iii) métodos e técnicas para aumento do engajamento entre as pessoas e os eventos de entretenimento; e (iv) tecnologias utilizadas como suporte à colaboração entre as pessoas;

2 - Identificar similaridades e diferenças entre as tecnologias utilizadas atualmente para dar suporte à colaboração entre multidões, considerando os diferentes métodos de colaboração (espontânea ou induzida).

3 - Identificar necessidades e desenvolver tecnologias visando o aumento do engajamento de multidões em eventos de entretenimento.

4 - Avaliar as tecnologias desenvolvidas através avaliações funcionais, de usabilidade e experiência de usuário (UX) e estudos de caso. Tais avaliações visam verificar a eficácia da aplicação em aumentar o engajamento ou a sensação de pertencimento da audiência de eventos de entretenimento.

\section{ASPECTOS DE INTERSEÇÃO DE SISTEMAS COLABORATIVOS E IHC}

Os trabalhos que este grupo de pesquisa tem desenvolvido no contexto das artes e eventos de entretenimento está situado bem na fronteira entre as áreas de Sistemas Colaborativos e IHC. Nesta seção, serão citados alguns trabalhos desenvolvidos e em andamento onde pontos de ambas as áreas serão destacados.

O projeto "Uma abordagem colaborativa na composição dinâmica de música", realizado em parceria com a FAARTES/UFAM, teve como objetivo dar suporte tecnológico à criação de paisagens sonoras colaborativas a partir da interação das pessoas em um mesmo espaço compartilhado. Este projeto resultou em uma dissertação de mestrado intitulada "Composição Musical Colaborativa Baseada Em Espacialização Sonora Em Tempo Real”. Nesse projeto de mestrado desenvolveu-se uma plataforma tecnológica que registra e reproduz em tempo real sons selecionados pelos usuários de um aplicativo específico, o Compomus, que interagem livremente em um ambiente delimitado. Dessa forma, a composição resultante da interação é um som que registra e reproduz em diferentes caixas de som o movimento dos usuários dentro do espaço de interação. Assim, foi possível analisar como os usuários interagiam uns com os outros, gerando sons diferentes a partir dessa interação. O som resultante é o produto da colaboração desses usuários no espaço compartilhado. A interação era observada entre os próprios usuários e entre esses e os sons reproduzidos [8,9].

Sobre o engajamento de multidões, o projeto de iniciação científica intitulado "Uma plataforma tecnológica para o engajamento de multidões no contexto de entretenimento" propôs uma plataforma para possibilitar uma maior interação de público de shows e eventos de massa com o espetáculo apresentado na forma de luzes e efeitos visuais através de smartphones e tablets [10]. A colaboração neste projeto é conseguida através da motivação do público em participar 
ativamente dos espetáculos. Os efeitos visuais só são visualizados em grande escala, onde cada usuário colabora sendo um ponto de luz formando um grane painel luminoso vivo. Desafios importantes do ponto de vista de IHC surgem, como: medida do engajamento do público em eventos de multidões, verificação da experiência do usuário no contexto de multidões, verificação da experiência da multidão, dentre outros. O projeto cresceu, ganhou visibilidade e foi utilizado no maior festival folclórico da região norte, o Festival de Parintins, tendo repercutido maciçamente na mídia local [11, 12]. O projeto conta, atualmente, com a colaboração de mais 1 aluno de doutorado e 2 alunos de iniciação científica.

\section{CONCLUSÃO}

O campo das artes e do entretenimento de multidões se mostra como um nicho de pesquisa a ser amplamente explorado. A tecnologia tem um potencial transformador com a capacidade de tornar expectadores passivos em agentes ativos criadores/transformadores das artes e interação com diversas formas de manifestações envolvendo multidões. Para tanto, faz-se necessária a integração de diversas áreas da computação de modo a gerar tais tecnologias transformadoras. As áreas de Sistemas Colaborativos, através de seus estudos de como pessoas podem colaborar umas com as outras em um espaço compartilhado afim de atingir um objetivo comum, e de IHC através do estudo das relações das interações entre as pessoas consistem nas principais responsáveis por viabilizar o suporte tecnológico nesse contexto não convencional.

Assim, desafios envolvendo a interação dessas duas grandes áreas de pesquisa apresentam-se, tais como: Como as pessoas devem colaborar no contexto de multidões? Como elas se comunicam ou coordenam suas atividades? Qual suporte tecnológico é necessário para viabilizar tal colaboração? Como se consegue engajamento das multidões com os eventos/instalações artísticas? Como se mede a experiência dessas multidões (individualmente ou coletiva)? Como se projeta sistemas para multidões?

Estas questões continuam em abertas e são convites à pesquisadores de ambas as áreas para estreitarem laços e produzirem resultados inovadores.

\section{REFERÊNCIAS}

1. Pierre Bourdieu. As regras da arte: gênese e estrutura do campo literário. Trad. Maria Lúcia Machado. São Paulo: Companhia das Letras, 1996.

2. Alcina Silva, Ana Paula Suarez, Andrea Umpierre, Glória Queiroz. Ciência e Arte: Um caminho de múltiplos encontros. Interacções, v. 13, n. 44, 2017. Disponível em: https://revistas.rcaap.pt/interaccoes/article/view/4109

3. D. Maynes-Aminzade, R. Pausch, and S. Seitz. 2002. Techniques for Interactive Audience Participation. In Proceedings of the 4th IEEE International Conference on Multimodal Interfaces (ICMI '02).
4. T. Roggla, C. Wand, L. P. Romero, J. Jansen, and P. Cesar. 2017. Tangible Air: An Interactive Installation for Visualising Audience Engagement. In Proceedings of the 2017 ACM SIGCHI Conference on Creativity and Cognition (C\&C '17). 263-265.

5. A. M. Webb, C. Wang, A. Kerne, and P. Cesar. 2017. Distributed Liveness: Understanding How New Technologies Transform Performance Experiences. In Proceedings of the 19th ACM Conference on Computer-Supported Cooperative Work \& Social Computing (CSCW '16). 432-437

6. G. K. STILL. 2000. Crowd Dynamics. Ph.D. Dissertation. University of Warwick, Coventry, UK

7. A. M. Webb, C. Wang, A. Kerne, and P. Cesar. 2017. Distributed Liveness: Understanding How New Technologies Transform Performance Experiences. In Proceedings of the 19th ACM Conference on Computer-Supported Cooperative Work \& Social Computing (CSCW '16). 432-437

8. Mauro Júnior Batista Amazonas. Composição musical colaborativa baseada em espacialização sonora em tempo real. 2017. 100 f. Dissertação (Mestrado em Informática) - Universidade Federal do Amazonas, Manaus, 2017. Disponível em: https://tede.ufam.edu.br/handle/tede/6111

9. Amazonas, M., Vasconcelos, V., Brandão, A., Kienem, G., Castro, T., Gadelha, B., \& Fuks, H. (2018, July). Collaborative Music Composition Based on Sonic Interaction Design. In International Conference on Distributed, Ambient, and Pervasive Interactions (pp. 335-346). Springer, Cham.

10. Victor Vasconcelos, Mauro Amazonas, Thais Castro, Rosiane de Freitas, Bruno Gadelha. Assistir ou Imergir? Redefinindo seu papel em grandes espetáculos. IHC 2018 (aceito para apresentação e publicação).

11. A Crítica. Caprichoso anuncia app de celular para criar mosaicos de led na galera azulada. Matéria publicada em: 23/06/2018. Disponível em:

https://www.acritica.com/videos/caprichoso-anunciaapp-de-celular-para-criar-mosaicos-de-led-na-galeraazulada

12. Em Tempo. Professores da UFAM desenvolvem aplicativo para Festival de Parintins. Publicado em 26/06/2018. Disponível em: http://d.emtempo.com.br/amazonas/110197/professores -da-ufam-desenvolvem-aplicativo-para-festival-deparintins 